\title{
CORRESPONDENCE
}

\section{SPONTANEOUS REGRESSION OF RETINOBLASTOMA}

\section{To the Editorial Committee of the BRITISH JouRNAL OF OPHTHALMOLOGY}

SIRs,--In the July number of the British Journal of Ophthalmology $(1965,49,381)$ Drs. Mehra and Banerji report a very interesting case of spontaneous regression of retinoblastoma. They record that in the literature so far, 15 cases of spontaneous cure have been reported. Perhaps the most interesting case appears to have escaped their notice. It is reported in the Transactions of the Ophthalmological Society of the United Kingdom (1937, 57, pt 1, p. 173). Mr. Hine read a paper on spontaneous cure of retinal glioma in a large number of members of one family. In the first generation, a male patient had had one eye excised for glioma at the age of 2 years and had a healed lesion in the other eye. This patient had 5 children. One died at the age of 6 months and was said to be premature. Two died of bilateral tumours which were confirmed as retinoblastomas. The fourth one had an excision of one eye at the age of 3 months and the fifth one had bilateral healed lesions in the fundi.

I can carry this story a little further because ten years ago I saw a son of the fourth member of the second generation, who was $\mathbf{8}$ years of age, and who showed no abnormality in either fundus; the parents informed me that they had a daughter, aged 9 months, who so far showed no abnormality. They did tell me, however, that the fifth member of the second generation, who had bilateral healed lesions in his fundi, had had 3 children, that one had died at the age of 5 weeks, that another, then aged 11 years, had had both eyes enucleated, and that yet another, then aged 7, had had the left eye enucleated. It has been interesting to me to read again this paper by Mr. Hine, because in the discussion which followed, Sir John Parsons did suggest that possibly the eyes which had been enucleated in the earlier generations might have been removed for pseudo-gliomata. I have no doubt that if he knew of this involvement of the third generation, his views would have changed.

$$
\text { Yours faithfully, }
$$

\section{H. G. MOORE}

29 WAKe GreEn RoAd,

MOSELEY,

BIRMINGHAM, 13.

October 12, 1965.

\section{OBITUARY}

\section{JAROMfR KURZ}

Our readers will be sad to learn that Professor J. Kurz of the University of Prague died at the age of 70 on October 30, 1965. An eminent ophthalmologist, and a recipient of the Purkinje medal, he has long been the doyen of our specialty in Czechoslovakia. 